\title{
Prospects behind bars: Analyzing decisions under risk in a prison population
}

\author{
Thorsten Pachur \\ University of Basel, Basel, Switzerland \\ AND \\ Yaniv Hanoch and Michaela Gummerum \\ University of Plymouth, Plymouth, England
}

\begin{abstract}
Criminal activity often involves considerable risks. It is therefore not surprising that criminals have been speculated to differ from noncriminals in risk attitude. Yet, few data exist to support this assumption. Moreover, the psychological underpinnings of differences in risk attitude are currently little understood. We presented prisoners and controls with sets of risky decision tasks and modeled their responses using cumulative prospect theory (CPT). The two groups showed several differences. Prisoners were more risk seeking than nonprisoners in lotteries involving losses, but they were less risk seeking in lotteries involving high-probability gains. Bestfitting CPT parameters indicated a reduced sensitivity to outcomes, for both gains and losses, and a stronger loss aversion among prisoners. In addition, prisoners showed a diminished sensitivity to the probability of gains. Our results contribute to a better understanding of prisoners' risk attitudes and the underlying mechanisms that distinguish prisoners from nonprisoners and may thus help improve interventions designed to prevent crime.
\end{abstract}

Alphonse "Scarface" Capone, one of the most notorious American gangsters of the 20th century, contracted syphilis as a young man but left it untreated because "it had disappeared" (Brewer-Smyth, 2006). Untreated syphilis can lead to extreme risk-taking behavior, and it has been speculated that Capone's medical condition might have contributed to his criminal proclivities. Criminal activity often involves considerable risks, such as being injured during a violent attack or being imprisoned if caught during burglary, and, as in the case of Capone, it is hypothesized that criminals differ from noncriminals in terms of their willingness to take risks (Becker, 1968; Gottfredson \& Hirschi, 1990; Lombroso, 1911/2005; Thornton, 1985).

Do they? As compared with nonprisoners, prisoners have been shown to exhibit higher tendencies to engage in risky activities, such as substance abuse (e.g., Fazel, Bains, \& Doll, 2006), unsafe sex (e.g., Frost \& Tchertkov, 2002), and gambling (Lahn, 2005). Wilson and Daly (2006) reported that young offenders have higher sensation-seeking tendencies (which highly correlate with risk taking) than do high school students (but see Knust \& Stewart, 2002; Stewart \& Hemsley, 1984). Concerning tasks involving financial risks (e.g., lotteries), which are an established method for investigating risk attitude, we are aware of only two studies that have used such an approach to contrast prisoners' and nonprisoners' risk taking. Block and Gerety (1995) studied prisoners' and students' responses to monetary risks, where the amount and probability of winning and losing varied. When only gains were involved, prisoners and nonprisoners exhibited similar risk-taking patterns. When faced with the possibility of losses, however, prisoners were significantly more likely to take risks. Furthermore, nonprisoners' behavior was mainly driven by the magnitude of the loss, whereas that of prisoners was largely driven by the probability of loss. Comparing students, entrepreneurs, and prisoners on a gambling task, Faragó, Kiss, and Boros (2008) reached similar conclusions.

What underlies differences between prisoners and nonprisoners in their willingness to take risks? One useful approach for revealing the cognitive underpinning of behavior is to describe it using cognitive models (e.g., Yechiam et al., 2008). Here, we use cumulative prospect theory (CPT; Tversky \& Kahneman, 1992) as a cognitive model to examine differences between prisoners and nonprisoners in risky choice. Several studies have used CPT as a framework to study individual differences (e.g., Booij, van Praag, \& van de Kuilen, 2010; Fehr-Duda, de Gennaro, \& Schubert, 2006). Although CPT is often regarded as being mute with regard to the exact cognitive operations underlying the information processing involved in people's choices (e.g., how information is searched and integrated; cf. Brandstätter, Gigerenzer, \& Hertwig, 2006; Payne, Bettman, \& Johnson, 1993), it nevertheless captures important cognitive regularities of choice behavior.

Y.Hanoch, yaniv.hanoch@plymouth.ac.uk 
Specifically, CPT disentangles the decision maker's sensitivity to differences in the outcomes (captured by the value function), sensitivity to differences in the probability of obtaining the outcomes (captured by the weighting function), and relative weighting of positive and negative outcomes (e.g., loss aversion). ${ }^{1}$

According to CPT, the subjective value of an outcome $x$ follows from the value function

$$
v(x)=\left\{\begin{array}{c}
x^{\alpha}, \text { if } x \geq 0 . \\
-\lambda(-x)^{\beta}, \text { if } x<0 .
\end{array}\right.
$$

The parameters $\alpha$ and $\beta$ reflect the sensitivity to differences in gain and loss outcomes, respectively, and are assumed to be smaller than 1, yielding a concave value function for gains and a convex value function for losses. The parameter $\lambda$ reflects the relative weight of gains and losses, with $\lambda>1$ indicating loss aversion.

With outcomes $x_{1} \leq \ldots \leq x_{k} \leq 0 \leq x_{k+1} \leq \ldots \leq x_{n}$, the weight $\pi^{+}\left(\pi^{-}\right)$given to a positive (negative) outcome $x$ is the difference between the probability of receiving an outcome at least as good (bad) as $x$ and the probability of receiving an outcome better (worse) than $x$ :

$$
\begin{aligned}
\pi_{i}^{+}= & w^{+}\left(p_{i}+\ldots+p_{n}\right)-w^{+}\left(p_{i+1}+\ldots+p_{n}\right) \\
& \quad \text { for } k<i<n ; \\
\pi_{j}^{-}= & w^{-}\left(p_{1}+\ldots+p_{j}\right)-w^{-}\left(p_{1}+\ldots+p_{j-1}\right) \\
& \text { for } 1<j \leq k .
\end{aligned}
$$

$w^{+}(p)$ and $w^{-}(p)$ are the weighting functions of the probabilities for gains and losses, respectively:

$$
\begin{aligned}
& w^{+}(p)=\frac{p^{\gamma}}{\left(p^{\gamma}+(1-p)^{\gamma}\right)^{1 / \gamma}} ; \\
& w^{-}(p)=\frac{p^{\delta}}{\left(p^{\delta}+(1-p)^{\delta}\right)^{1 / \delta}} .
\end{aligned}
$$

The parameters $\gamma$ and $\delta$ reflect the sensitivity to probability differences and are assumed to be smaller than 1 . This yields overweighting of small probabilities and underweighting of moderate to large probabilities, with the exact crossover point varying as a function of $\gamma$ and $\delta$ (for an extended discussion, see Gonzalez \& $\mathrm{Wu}, 1999)$.

The overall value of option $A, V(A)$, is determined as

$$
V(A)=\sum_{j=1}^{k} v\left(x_{j}\right) \pi_{j}^{-}+\sum_{i=k+1}^{n} v\left(x_{i}\right) \pi_{i}^{+} .
$$

When comparing different options, CPT predicts that the option with the more attractive $V$ will be chosen.

Here, we report a study in which prisoners and nonprisoners were asked to choose between (hypothetical) monetary risky options. Our goals were (1) to examine the degree to which prisoners and nonprisoners exhibit established choice phenomena (in particular, the fourfold pattern; Tversky \& Kahneman, 1992) and (2) to apply CPT to investigate potential differences in risky decision making between prisoners and nonprisoners.

\section{METHOD}

\section{Participants}

Prison participants were 51 sentenced adult males from a medium security prison in the U.K., from 21 to 72 years of age $(M=$ 41.8 years, $S D=13.6$ ). The mean length of sentence was 23.5 years $(S D=37.8)$. Fifty-one percent of the participants were sentenced for an offense against a person (including murder, violence, and sexual assault), $45.1 \%$ for crimes not against a person (drugs, burglary), and $3.9 \%$ for other offenses. The control sample consisted of 50 male nonprisoners from the U.K. drawn from the general population but matched to the prisoners in terms of age ( $M=42.0$ years, $S D=$ 16.0) $[t(99)=0.22, p=.94]$. Although we were unable to obtain education information about the prisoners, data on another sample from the same prison population (Hanoch \& Gummerum, in press), suggest that the control participants were better educated than the prisoners. For instance, $24 \%$ and $58 \%$ of our control participants, but only $2 \%$ and $40 \%$ of the prisoners indicated A-levels and the General Certificate of Secondary Education (GCSE), respectively, as their highest educational attainment. Nevertheless, additional analyses suggested that education had no major influence on our results. First, the results for our control group were almost identical to those collected in a pilot study for a student sample, who had considerably higher education levels than our control sample. ${ }^{2}$ Second, the results remained stable when we focused on only those participants in the control group with low education levels (i.e., excluding those with A-levels or higher).

\section{Materials}

Participants were presented with five sets of lottery tasks containing a total of 115 choices. Four sets involved choices between a lottery and a sure outcome, where two sets consisted of possible gains only and two consisted of possible losses only. Within the gain (loss) sets, the lottery offered either a $5 \%$ or a $95 \%$ chance of winning (losing) $£ 100$, and the outcome $x$ of the sure option was varied between a gain (loss) of $£ 0$ and $£ 100$, in steps of $£ 5$. Within each of the four sets, each participant made 21 decisions. The fifth set (mixed prospects) asked participants to indicate whether they would choose a lottery that involved a $50 \%$ chance of losing $£ 50$ and a $50 \%$ chance of winning $x$ (Tversky \& Kahneman, 1992). The amount $x$ was varied from $£ 0$ to $£ 600$, in steps of $£ 20$, so that each participant made 31 decisions. The order of the five tasks was counterbalanced.

\section{Procedure}

The research protocol was approved by both the prison and the university institutional review boards. Prisoners were approached inside the prison and informed that participation was voluntary (with no monetary compensation) and anonymous and that they would incur no negative consequences as a result of participating (or not). Prisoners were tested individually in a designated room where they were provided with both oral and written instructions. At all times, one of the research assistants was present in the room to answer possible clarification questions. The nonprisoners were paid $£ 3$ for taking part in the study.

\section{RESULTS}

In a first step, we quantified each participant's risk attitude by deriving certainty equivalents (CEs) for the four task sets involving either only gains or only losses. Specifically, we determined for each set the amount of $x$ at which a participant switched from preferring the lottery to preferring the sure outcome (gain sets) or vice versa (loss sets). The CE was defined as the midpoint between this amount and the next lower amount at which the lottery was still preferred. Participants who switched back and forth between a preference for the lottery and a preference for 
the sure outcome- depending on the task set, $7 \%-39 \%$ of the prisoners and $2 \%-13 \%$ of the nonprisoners - were excluded from this analysis. Data from all participants were used, however, in the modeling analysis below. On the basis of the CE, we calculated the relative risk premium (RP), defined as

$$
\text { relative } \mathrm{RP}=\frac{\mathrm{EV}-\mathrm{CE}}{|\mathrm{EV}|},
$$

where EV refers to the expected value of the lottery. A negative RP indicates risk seeking, and a positive RP indictes risk aversion. Figure 1 shows the average relative RP in the four sets of tasks, separately for the prisoners and the nonprisoners. As can be seen, both groups exhibit the typical fourfold pattern: risk seeking in the low-probability gain and high-probability loss sets, and risk aversion in the high-probability gain and the low-probability loss sets. Still, prisoners were more risk seeking than the nonprisoners in both loss sets [low probability, $t(84)=-2.1, p=$ .04 ; high probability, $t(87)=-2.3, p=.02]$, whereas the opposite was true in the set involving a high-probability gain $[t(86.1)=3.1, p=.003]$. The two groups did not differ in the set involving a low-probability gain $[t(93)=$ $0.50, p=.62]$.

For the fifth task set (mixed prospects), prisoners $(M=$ 189.0, $S D=128.9)$ and nonprisoners $(M=157.8, S D=$ 107.1) did not differ in terms of the amount at which they found the 50:50 option equally attractive to receiving nothing $[t(78)=1.2, p=.24]$. Both groups indicated, on average, an amount that was significantly higher than $£ 100$ [prisoners, $t(30)=3.9, p=.001$; nonprisoners, $t(48)=3.8, p=.001]$. Both prisoners and nonprisoners thus seemed to display loss aversion. ${ }^{3}$

In the next step, we modeled participants' choices using CPT. To do so, we first determined for each amount of the sure option (for the four sets involving either only gains or only losses) and for each amount of the lottery's positive outcome (for the mixed prospects set) the proportion of prisoners and nonprisoners, respectively, choosing the lottery. We then fitted CPT to these proportions; that is, CPT predicted the probability that the lottery, $L$, was chosen over the sure outcome, $S$. To achieve some generality, we fitted across all five task sets simultaneously. For predicting the probability of choosing $L$ over $S, P(L, S)$, we used the Luce choice rule (Luce, 1959; cf. Rieskamp, 2008):

$$
P(L, S)=\frac{e^{\phi \cdot V(L)}}{e^{\phi \cdot V(L)}+e^{\phi \cdot V(S)}},
$$

where $\phi>0$ is a consistency parameter, specifying how sensitively the model reacts to differences in the options' subjective values. A common psychological interpretation of the consistency parameter is that it captures the degree to which decisions are random or haphazard (with lower values indicating lower consistency; cf. Bishara et al., 2009). CPT had, thus, a total of six parameters: two for the sensitivity to differences in outcomes ( $\alpha$ and $\beta$ for the gain and loss domains, respectively), two for the sensitivity to differences in probability ( $\gamma$ and $\delta$ for the gain and loss domains, respectively), a loss aversion parameter $(\lambda)$, and a consistency parameter $(\phi)$.

To reflect main assumptions of CPT, the parameter values were restricted as follows: $0<\alpha \leq 1 ; 0<\beta \leq 1$; $0<\lambda \leq 10 ; 0<\gamma \leq 1 ; 0<\delta \leq 1 ; 0<\phi \leq 10$ (cf. Rieskamp, 2008). For instance, for the assumed concave value function in the gain domain, $\alpha$ needs to be smaller than 1 ; for a weighting function reflecting the assumed overweighting of small probabilities and underweighting of moderate to large probabilities, $\gamma$ needs to be smaller than 1 .

We determined, for prisoners and nonprisoners separately, the set of parameters that produced a trajectory of the predicted choice proportions (across the different

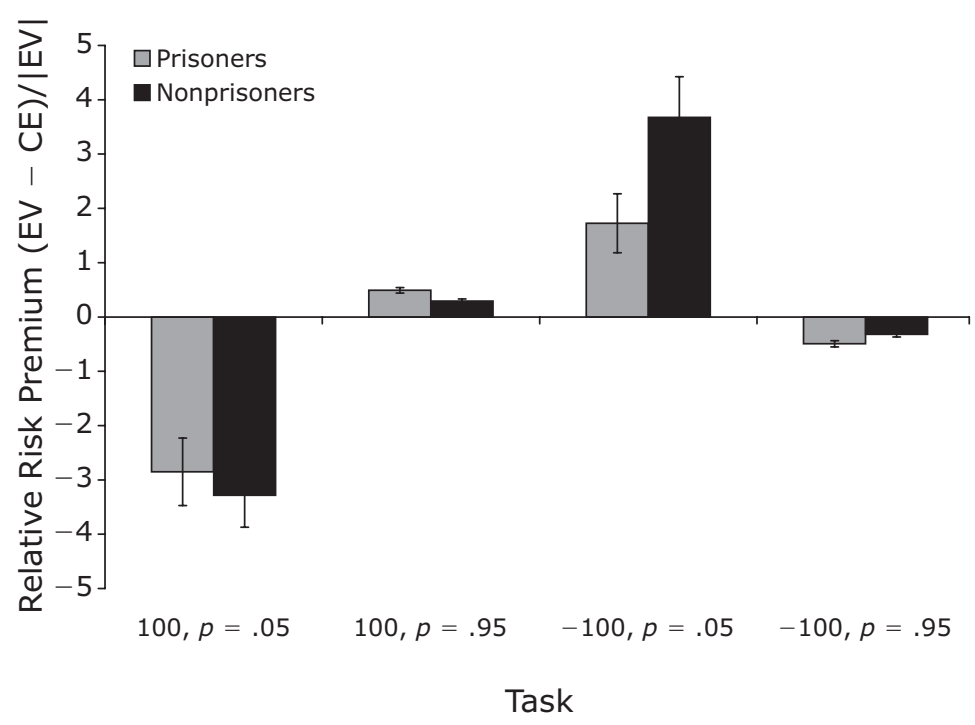

Figure 1. Relative risk premium (defined as the expected value of a lottery minus the certainty equivalent, divided by the absolute expected value), separately for prisoners and nonprisoners. Error bars indicate $\pm 1 S E M$. 


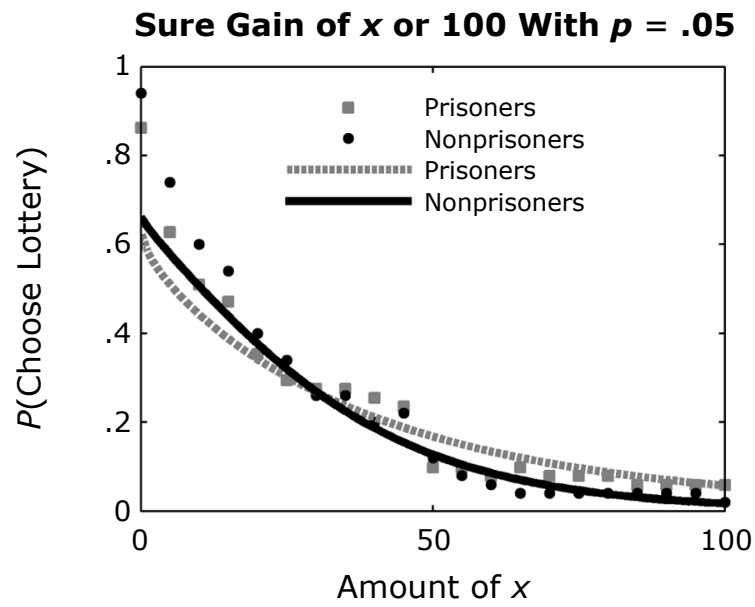

Sure Gain of $x$ or 100 With $p=.95$
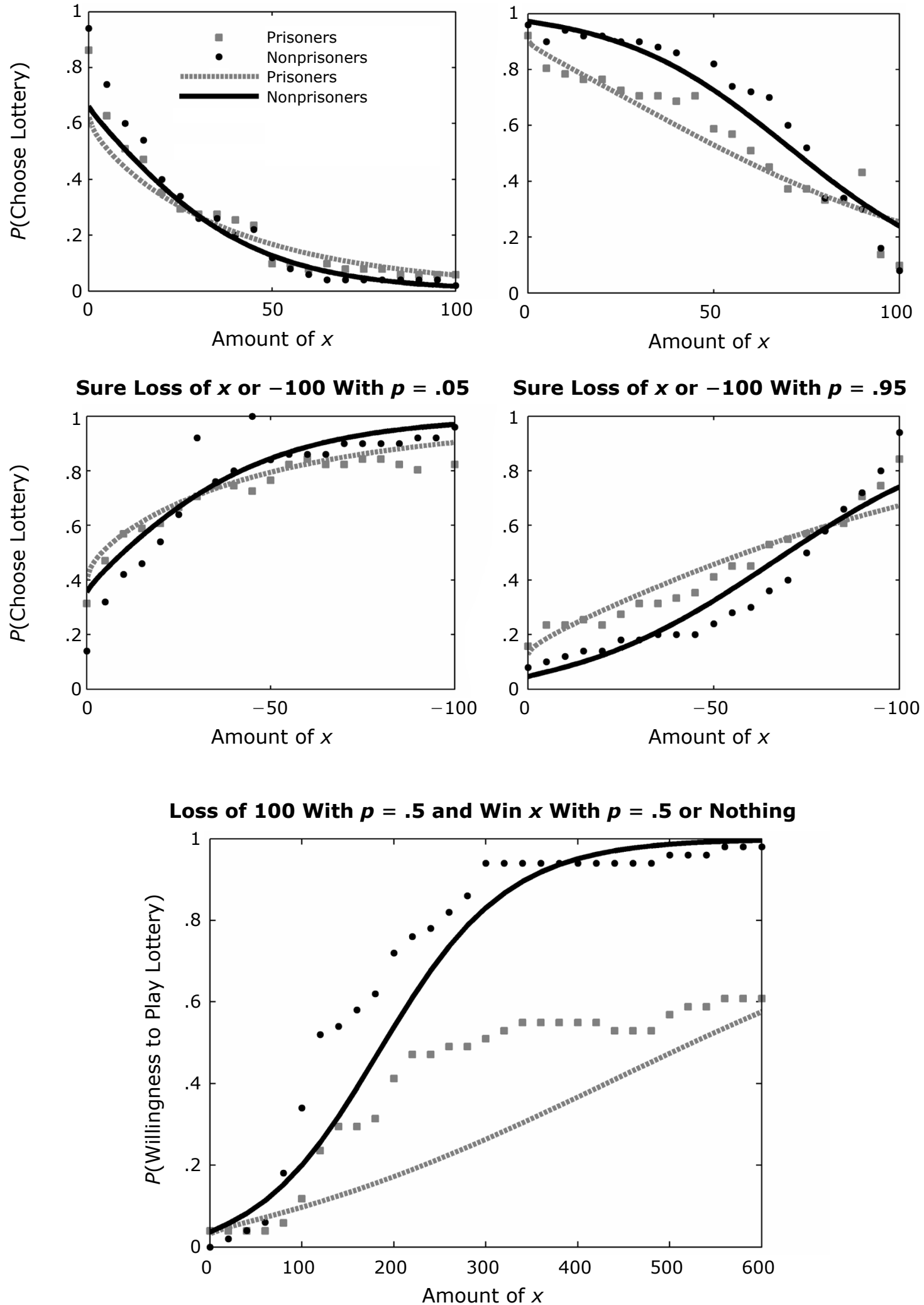

Figure 2. Observed and predicted (based on cumulative prospect theory) probability to choose the lottery in the five sets of tasks, separately for prisoners (gray squares and gray dashed line) and nonprisoners (black circles and black solid line). 
amounts of $x$ ) that showed the smallest deviation from the observed trajectory. As a deviation measure, $G^{2}$ was used (e.g., Sokal \& Rohlf, 1994), with a smaller $G^{2}$ indicating a better fit. For the fitting analysis, in a first step, a grid search was used to identify the best parameters for minimizing $G^{2}$, and then the 20 best-fitting grid values were used as starting points for subsequent optimization using the simplex method (Nelder \& Mead, 1965), as implemented in MATLAB. ${ }^{4}$

Figure 2 shows for all five task sets the trajectory predicted on the basis of the best-fitting parameter set. Overall, the model fit was better for the nonprisoners $\left(G^{2}=\right.$ $9,712.4)$ than for the prisoners $\left(G^{2}=12,886\right)$. Therefore, the overall $G^{2}$, assuming a separate set of parameters for the two groups, was 22,598.4. To test for differences between the prisoners and the nonprisoners, we additionally fitted, for each parameter, a model that assumed no differences between the two groups on the respective parameter. For each of these constrained models, the decrease in fit relative to the unconstrained model was tested for significance using a likelihood ratio test (cf. Wong, 1994). ${ }^{5}$

The best-fitting parameter values and the results of the significance tests are shown in Table 1. The prisoners and the nonprisoners showed substantial differences on most parameters. First, the prisoners' lower $\alpha$ and $\beta$ suggest a reduced sensitivity to differences both for gains and for losses. Moreover, as indicated by the differences on $\lambda$, prisoners exhibited a stronger loss aversion than did nonprisoners. In addition, the prisoners' lower $\gamma$ indicates a lower sensitivity to differences in probability of gains. In other words, prisoners are less discriminative than nonprisoners as to whether an option's possible gain is likely or unlikely. Finally, the consistency parameter $(\phi)$ indicated differences in choice consistency. Interestingly, the prisoners seemed to show a more deterministic choice behavior. ${ }^{6}$ There were no differences concerning the sensitivity to differences in the probability of losses (as captured by $\delta$ ).

\section{DISCUSSION}

In his seminal work, Becker (1968) proposed that criminals may be distinguished from noncriminals by, among other things, an elevated willingness to take risksespecially in decisions involving losses. We modeled pris- oners' and nonprisoners' decision making under risk using CPT, thus providing a detailed analysis of prisoners' and nonprisoners' risk attitudes. Although both groups showed the fourfold pattern (see Figure 1), prisoners showed a higher tendency to take risks when a loss was likely, consistent with earlier studies (Block \& Gerety, 1995; Faragó et al., 2008). When only gains were involved, however, prisoners showed a lower tendency to take risks, but only when the probability was high (e.g., 95\%). Best-fitting CPT parameters suggested that prisoners have a lower sensitivity to changes in outcomes, for both gains and losses, and are more loss averse than nonprisoners. Additionally, prisoners appeared to be less sensitive to differences in probabilities of experiencing a gain; prisoners and nonprisoners did not differ in their sensitivity to differences in probabilities of experiencing a loss.

Why did prisoners and nonprisoners differ in their risky decision making? First, although our additional analyses did not suggest that education was a main factor driving the observed differences, future research will need to examine the role of education more systematically. Second, differences could result from economic factors. Given that prisoners have fewer economic resources available than do nonprisoners, however, one should expect the prisoners to show higher (rather than lower) sensitivity to differences in outcomes. Our results might, thus, even be conservative. Third, our results could reflect differences in personality - in particular, the willingness to accept risks. Fourth, the prison environment might contribute to the observed differences. For instance, the prisoners' diminished sensitivity to outcome differences might be due to the limited opportunity to make purchases within prisons. Their reduced loss aversion might be due to a loss of power resulting from imprisonment (Inesi, 2010). It would, therefore, be interesting to analyze the risk attitude of former prisoners.

It has been suggested that differences in risk taking can be accounted for by differences in risk perception (e.g., Hanoch, Johnson, \& Wilke, 2006; Weber \& Hsee, 1998). The differences in risk attitude between prisoners and nonprisoners observed in our study, however, are unlikely to be due to differences in risk perception, because all participants were provided with the same risk information (i.e., probabilities). Nevertheless, differences in risk perception between prisoners and nonprisoners might con-

Table 1

Results of Fitting Cumulative Prospect Theory (CPT) to Prisoners' and Nonprisoners' Decisions

\begin{tabular}{|c|c|c|c|c|c|c|c|}
\hline \multirow[b]{2}{*}{ Group } & \multicolumn{6}{|c|}{ CPT Parameters } & \multirow[b]{2}{*}{$G^{2}$} \\
\hline & $\alpha$ & $\beta$ & $\gamma$ & $\delta$ & $\lambda$ & $\phi$ & \\
\hline Prisoners & .645 & .595 & .497 & .541 & 2.687 & 0.170 & $12,886.0$ \\
\hline Nonprisoners & .864 & .832 & .569 & .554 & 1.777 & 0.088 & $9,712.4$ \\
\hline$\Delta G^{2}$ of model in which parameter & & & & & & & \\
\hline was set to be equal for both groups & 85.600 & 64.600 & 15.600 & 0.600 & 38.600 & 30.600 & \\
\hline$p$ & .001 & .001 & .001 & .440 & .001 & .001 & \\
\hline
\end{tabular}

Note-Shown are the results for the model that assumes separate sets of parameters for prisoners and nonprisoners. For each parameter, the significance of the decrease in model fit (i.e., $\Delta G^{2}$ ) is shown when the respective parameter was constrained to be equal for both groups. The parameters $\alpha$ and $\beta$ reflect sensitivity to outcome differences in the gain and loss domains, respectively; $\gamma$ and $\delta$ indicate sensitivity to differences in probability in the gain and loss domains, respectively; $\lambda$ indicates the amount of loss aversion; and $\phi$ indicates choice consistency. 
tribute to potential differences in taking real-world risks, where probabilities need to be judged subjectively.

\section{Implications}

Our results contribute to a better characterization of risk attitudes of prisoners. This refined picture could inform policy makers, who have relied on deterrence theory to derive strategies for battling crime. Economists and criminologists have continuously debated whether increasing the level of punishment or increasing the likelihood of being caught has a stronger deterrence effect (Polinsky \& Shavell, 2000). Our results suggest that, as compared with nonprisoners, prisoners will be relatively insensitive to increases in punishment (or incentive).

Likewise, our work may contribute to the development of improved enhanced thinking skills (ETS) programs in prisons. ETS programs aim at reducing reconvictions by changing prisoners' criminal attitudes (so far, with limited success; e.g., Falshaw, Friendship, Travers, \& Nugent, 2004). Current ETS programs mainly address prisoners' impulsive tendencies, moral reasoning, and empathic behavior (McDougall, Perry, Clarbour, Bowles, \& Worthy, 2009), whereas their risk taking has received no attention so far. Designing ETS programs that include sessions on understanding and changing prisoners' risk attitudes - for instance, by enhancing their limited sensitivity to the consequences of risk behavior and to the probability of gaining something - might help reduce recidivism.

\section{AUTHOR NOTE}

The first two authors contributed equally. We thank Mandeep Dhami, Itiel Dror, Daniel Kahneman, Timothy J. Pleskac, and two anonymous reviewers for comments on earlier drafts, Jörg Rieskamp for advice with the modeling, Laura Wiles for editing the manuscript, and all of the participants and prison authorities for making this study possible. Correspondence concerning this article should be addressed to Y. Hanoch, School of Psychology, University of Plymouth, Drake Circus, Plymouth PL4 8AA, England (e-mail: yaniv.hanoch@plymouth.ac.uk).

\section{REFERENCES}

Abdellaoui, M., Bleichrodt, H., \& L'Haridon, O. (2008). A tractable method to measure utility and loss aversion under prospect theory. Journal of Risk \& Uncertainty, 36, 245-266.

BECKER, G. S. (1968). Crime and punishment: An economic approach. Journal of Political Economy, 76, 169-217.

Bishara, A. J., Pleskac, T. J., Fridberg, D. J., Yechiam, E., Lucas, J., BUSEMEYER, J. R., ET AL. (2009). Similar processes despite divergent behavior in two commonly used measures of risky decision making. Journal of Behavioral Decision Making, 22, 435-454.

Block, M. K., \& Gerety, V. E. (1995). Some experimental evidence on differences between student and prisoner reactions to monetary penalties and risk. Journal of Legal Studies, 24, 123-138.

BooiJ, A. S., van Praag, B. M. S., \& van de Kuilen, G. (2010). A parametric analysis of prospect theory's functionals for the general population. Theory \& Decision, 68, 115-148.

Brandstätter, E., Gigerenzer, G., \& Hertwig, R. (2006). The priority heuristic: Making choices without trade-offs. Psychological Review, 113, 409-432.

BREWER-SMYTH, K. (2006). Neurological correlates of high-risk behavior: A case study of Alphonse Capone. Journal of Neuroscience Nursing, 38, 442-446.

Erev, I., Ert, E., \& Yechiam, E. (2008). Loss aversion, diminishing sensitivity, and the effect of experience on repeated decisions. Journal of Behavioral Decision Making, 21, 575-597

Falshaw, L., Friendship, C., Travers, R., \& Nugent, F. (2004).
Searching for "what works": HM Prison Service accredited cognitive skills programmes. British Journal of Forensic Practice, 6, 3-13.

FARAGó, K., Kiss, O., \& Boros, J. (2008). Risk-taking in entrepreneurs, compared to criminals and students: The role of uncertainty and stakes. Journal of Socio-Economics, 37, 2231-2241.

Fazel, S., Bains, P., \& Doll, H. (2006). Substance abuse and dependence in prisoners: A systematic review. Addiction, 101, 181-191.

Fehr-Duda, H., De Gennaro, M., \& Schubert, R. (2006). Gender, financial risk, and probability weights. Theory \& Decision, 60, 283313.

Frost, L., \& TChertkov, V. (2002). Prisoner risk taking in the Russian Federation. AIDS Education \& Prevention, 14(Suppl. B), 7-23.

Gonzalez, R., \& Wu, G. (1999). On the shape of the probability weighting function. Cognitive Psychology, 38, 129-166.

GotTFREDSON, M. R., \& Hirschi, T. (1990). A general theory of crime. Palo Alto, CA: Stanford University Press

Hanoch, Y., \& Gummerum, M. (in press). A comparison of the risktaking behaviors of prisoners and nonprisoners. Journal of Behavioral Decision Making. doi:10.1002/bdm.701

Hanoch, Y., Johnson, J. G., \& Wilke, A. (2006). Domain specificity in experimental measures and participant recruitment: An application to risk-taking behavior. Psychological Science, 17, 300-304.

INESI, M. E. (2010). Power and loss aversion. Organizational Behavior \& Decision Processes, 112, 58-69.

Knust, S., \& Stewart, A. L. (2002). Risk-taking behavior and criminal offending: An investigation of sensation seeking and the Eysenck Personality Questionnaire. International Journal of Offender Therapy \& Comparative Criminology, 46, 586-602.

LAHN, J. (2005). Gambling among offenders: Results from an Australian survey. International Journal of Offender Therapy \& Comparative Criminology, 49, 343-355.

Lombroso, C. (2005). Criminal man. Durham, NC: Duke University Press. (Original work published 1911)

LUCE, R. D. (1959). Individual choice behavior: A theoretical analysis. New York: Wiley.

McDougall, C., Perry, A. E., Clarbour, J., Bowles, R., \& WorTHY, G. (2009). Evaluation of HM Prison Service enhance thinking skills programme: Report on the outcomes from a randomised controlled trial. Retrieved 29 September, 2009, from www.justice.gov .uk/publications/docs/report-on-the-outcomes-from-a-randomised -controlled-triall.pdf.

Nelder, J. A., \& MEAD, R. (1965). A simplex method for function minimization. Computer Journal, 7, 308-313.

Payne, J. W., Bettman, J. R., \& Johnson, E. J. (1993). The adaptive decision maker. Cambridge: Cambridge University Press.

Polinsky, A. M., \& Shavell, S. (2000). The economic theory of public enforcement of law. Journal of Economic Literature, 38, 45-76.

Rieskamp, J. (2008). The probabilistic nature of preferential choice. Journal of Experimental Psychology: Learning, Memory, \& Cognition, 34, 1446-1465.

SoKal, R. R., \& RohlF, F. J. (1994). Biometry: The principles and practices of statistics in biological research (3rd ed.). New York: Freeman.

Stewart, C. H. M., \& Hemsley, D. R. (1984). Personality factors in the taking of criminal risks. Personality \& Individual Differences, 5, 119-122.

Thornton, D. (1985). Rate of offending, risk-evaluation and riskpreference. Personality \& Individual Differences, 6, 127-128.

TVersky, A., \& Kahneman, D. (1992). Advances in prospect theory: Cumulative representation of uncertainty. Journal of Risk \& Uncertainty, 5, 297-323.

Weber, E. U., \& Hsee, C. (1998). Cross-cultural differences in risk perception, but cross-cultural similarities in attitudes towards perceived risk. Management Science, 44, 1205-1217.

Wilson, M., \& DALY, M. (2006). Are juvenile offenders extreme future discounters? Psychological Science, 17, 989-994.

WoNG, R. S.-K. (1994). Model selection strategies and the use of association models to detect group differences. Sociological Methods \& Research, 22, 460-491.

Yechiam, E., Kanz, J. E., Bechara, A., Stout, J. C., Busemeyer, J. R., Altmaier, E. M., \& Paulsen, J. S. (2008). Neurocognitive deficits related to poor decision making in people behind bars. Psychonomic Bulletin \& Review, 15, 44-51. 


\section{NOTES}

1. For instance, a reduced sensitivity to probability information, as captured by CPT's weighting function, could be due to the use of a noncompensatory heuristic that sometimes ignores probability information.

2. For instance, $56 \%$ of the control sample, but $0 \%$ of the student sample, indicated a GCSE, and only $24 \%$ of the control sample, but $78 \%$ of the students, indicated A-levels as their highest educational attainment.

3. But note that the manifestation of loss aversion can differ between different types of decision tasks (see, e.g., Erev, Ert, \& Yechiam, 2008).

4. Note that it has been proposed to estimate $\lambda$ independently of $\alpha$ and $\beta$ (e.g., Abdellaoui, Bleichrodt, \& L'Haridon, 2008). Therefore, we also implemented a stepwise procedure in which we first fitted all param- eters except $\lambda$ on the four sets involving either only gains or only losses, and then we used the resulting best-fitting values to fit $\lambda$ in the mixedprospects set. As it turned out, this procedure yielded the same qualitative pattern as when all parameters were estimated simultaneously.

5. Specifically, the probability of the difference between the two models $\left(\Delta G^{2}\right)$ is that of a chi-square of $\Delta G^{2}$ with 1 degree of freedom (since the number of free parameters of the unconstrained model and the constrained models differ by one: 11 vs. 12).

6. Using the Iowa Gambling Task, Yechiam et al. (2008) found some evidence for a lower choice consistency among prisoners than among nonprisoners.

(Manuscript received December 19, 2009; revision accepted for publication April 22, 2010.) 